\title{
Lo fantástico verosímil. Análisis de los tipos de verosimilitud en la serie Game of Thrones
}

\author{
María de Lourdes López Gutiérrez ${ }^{1 *}$
}

\begin{abstract}
Resumen
Las audiencias de la serie Game of Thrones, (HBO, 2011), han ido en aumento desde su estreno. El enganche de un público heterogéneo ha convertido a Game of Thrones en un fenómeno mediático cuyo éxito puede deberse a diversos factores, entre ellos la verosimilitud de la historia, que puede resultar convincente para espectadores que buscan historia fantástica, una trama de poder o una serie de época. Abordamos los principios de la verosimilitud, entendidos como la factibilidad de una historia para resultar lógica y posible ante los ojos del espectador. Los primeros postulados de lo verosímil aparecen en la Poética de Aristóteles, pero son sólidamente desarrollados por la semiótica del siglo XX, en los trabajos de Todorov, Kristeva y Metz, que constituyen el marco del que derivamos las categorías de análisis de los distintos tipos de verosimilitud: semántica, sintáctica, genérica y diegética. El análisis de la verosimilitud de la serie, apunta a la lógica espacio temporal del relato y a la sucesión articulada de acciones de personajes cuya trayectoria responde a la causalidad y que, por tanto, adquiere el estatus de verosímil, aun cuando se trate de personajes que se mueven en un mundo imaginario.

Abstract

The audience of Game of Thrones (HBO, 2011), has been increasing since its premiere. The loyalty of a heterogeneous audience has turned Game of Thrones into a media phenomenon whose success may be due to different factors, for example the verosimilitude of the story, which can be convincing for viewers who look for a fantasy story, a plot of power or a time series. We approach the principles of verisimilitude, understood as the feasibility of a story to be logical and possible for the viewer. The first postulates appeared in the Poetics of Aristotle, but are solidly developed by the semiotics of the 20th century, in the works of Todorov, Kristeva and Metz, which constitute the framework from which we derive the categories of analysis of the different types of verisimilitude: semantic, syntactic, generic and diegetic. The analysis of the likelihood of the series, points to the logical temporal space of the story and the articulated succession of actions of characters whose trajectory responds to the causality and, therefore, acquires the status of credible, even when dealing with characters that move in an imaginary world.
\end{abstract}

Palabras Clave

Verosimilitud, Series televisivas, Game of Thrones, Semántica, Sintáxis, diégesis.

Keywords

Verisimilitude, Television series, Game of Thrones, Semantics, Syntax, Diegesis.

${ }^{1}$ Universidad Panamericana. Ciudad de México

*Autor para correspondencia: mllopezg@up.edu.mx

\section{Introducción}

El 17 de abril de 2011 se estrenó Game of Thrones (GOT), en HBO, la televisora que había revolucionado el mundo de la ficción televisiva desde su audaz propuesta temática y formal de Oz y Los Soprano (Tubau, 2014). Desde el estreno en el que aquellos primeros espectadores conocieron a los Caminantes blancos, a la ejemplar familia Stark y a los incestuosos Lannister, las audiencias de la serie se incrementaron de forma prácticamente exponencial. 
Según datos de HBO, el estreno de la última temporada, que tuvo lugar el 14 de abril de 2019, alcanzó los 17.4 millones de espectadores, casi el doble de los registrados al inicio de la séptima (AP, 15 de abril, 2019). Entre una temporada y otra, nuevas audiencias se sumaban recurriendo al binge watching para ponerse al corriente y poder ser partícipes de los esperados estrenos de cada nuevo episodio.

Esto convierte a GOT no solo en una de las series más vistas de la generación conocida como Tercera Edad de Oro de las series, sino en todo un fenómeno mediático que genera tráfico en las redes sociales, furor en las conversaciones y sobre todo una expectativa cada vez mayor sobre el final de la historia y el destino de los personajes(Entrepeneur, 2019) (Excelsior, 2019).

Quizás algunos espectadores, considerados como fidelizados, se tardaron en seguir la serie porque no les convencía el género fantástico, no les gustaban las series de época o nos les interesaba la violencia salvaje de un mundo que no existe. Sin embargo, muchos detractores iniciales fueron convenciéndose poco a poco que aquello no necesariamente es una serie fantástica, que la violencia es parte de un entorno en el que resulta pertinente, y que tampoco es una serie histórica, sino un relato articulado de manera clara, montada en una estructura narrativa compleja con una pléyade de personajes impredecibles cuyos arcos dramáticos, trazados algunos en una lamentable brevedad, constituyen un entramado que va poniendo en entredicho los valores humanos, sobre todo los apetitos de poder y los conceptos de justicia (Carrión, 2017) (López, 2012).

¿Cómo logra mantener a una audiencia tan numerosa e interesada una serie en la que aparecen dragones, resucitados, brujas y muertos vivientes? Estos elementos, para quienes no son fanáticos de la fantasía, pueden resultar en una serie de recursos poco serios que, más que producir una buena historia generan solo un espectáculo visual. Sin embargo, esas consideraciones, que seguramente aparecieron a lo largo de la serie, han ido pasando a segundo plano para lograr un pacto con el espectador que se ha entregado a la historia con una fruición propia del mejor cine o la mejor literatura.

Uno de los elementos que pueden ayudarnos a responder esta pregunta es el principio de verosimilitud que subyace en la historia y su forma de ser contada, es decir, en el relato. Un relato convincente, una historia que aparece como posible, una sucesión de acontecimientos basada en la causalidad, todo ello constituye el amplio concepto de la verosimilitud, que será desarrollado a continuación para posteriormente encontrar las categorías que hacen verosímil a GOT.

\section{El análisis de series de televisión}

Las series de televisión como objeto de estudio son un fenómeno relativamente emergente en el ámbito del análisis de fenómenos mediáticos. Si bien el serial televisivo ha ocupado un volumen considerable en la "pantalla chica", no es hasta el advenimiento de lo que se ha denominado "Segunda época de oro de las series" (Thompson, 1997) que la investigación académica la pone en la mira.

Obras como Complex TV (Mittel, 2015), o la intensa producción de autores como Cascajosa (2009, 2015), Carrión (2011), García (2014), recogen no solo la complejidad actual del serial televisivo sino las múltiples visiones y perspectivas desde la cual se puede realizar su abordaje.

La confluencia de múltiples discursos en un producto audiovisual como la serialidad televisiva, ha generado estudios de los mecanismos narrativos propios del serial, de la construcción y trazo dramático de múltiples personajes. También de los paradigmas estéticos que subyacen en el lenguaje utilizado, y en mayor medida de las series como fenómeno mediático que explota con las plataformas de visionado en línea y convierte al espectador en su propio programador.

Explorar los elementos que hacen que una serie sea verosímil es un trabajo que sin duda tiene que echar mano del campo de cultivo generado por estos autores, pero dada la emergencia del tema, es necesario también apoyar el aparato crítico en los autores que han abordado la verosimilitud en otros productos ficcionales, como la literatura y el cine, y que serán la base del análisis en este trabajo.

\section{1 ¿Qué es lo verosímil?}

Partamos de las diferencias entre realismo y verdad: “(...) para los lógicos la verdad es la relación entre una manifestación individual de una frase y un referente sobre la cual la frase afirma algo "(Ducrot y Todorov, 2005, p. 301). Pero en la ficción la verdad no es un atributo. 
El realismo está asociado más al tipo y al género de la obra. El tipo está configurado por ciertas propiedades estructurales mientras que el género permite al lector vincular la obra con otras ya conocidas. De ahí que Zavala (2007) indique que el género de una obra ficcional construye parte del horizonte de expectativas del espectador-lector.

Siguiendo este hilo de ideas, la verosimilitud se asoma como un concepto asociado al realismo, que no se determina por la fidelidad a la realidad sino por la solidez de los mecanismos internos que articulan y sostienen una historia lógica. Los inicios lejanos del concepto de verosimilitud se pueden atribuir a Córax de Siracusa, (Hernández y García, 1994), cuyos escritos no sobrevivieron al paso del tiempo, pero sí un número considerable de citas sobre la retórica utilizada en los tribunales.

Sus ideas se centraban en cómo ayudar a los ciudadanos a defender sus demandas utilizando la palabra como único argumento probatorio. Si el discurso parece verdad, será creíble para los demás, independientemente de su correspondencia con la verdad. En otras palabras, si lo dicho genera certeza tendrá aceptación por parte de quienes escuchan (Hernández y García, 1994).

Platón desarrolla una larga disquisición, entre Gorgias y Sócrates, al respecto de la retórica, como "autora" de la persuasión, que hace creer respecto de lo justo o de lo injusto utilizando recursos similares a la cocina y a la cosmética:

(... ) quizá me comprenderás así mejor, que lo que el tocador es a la gimnasia, es la cocina a la medicina; o mejor, que lo que el tocador es a la gimnasia es la sofística a la parte legislativa, y lo que la cocina es a la medicina es la Retórica al arte judicial. (Platón, trans.1871:161)

Si para Platón la retórica es el arte de la ilusión y el engaño, para Aristóteles es el arte de persuadir mediante el discurso. Aristóteles vincula la posibilidad de persuasión de un discurso a la lógica con la que este es expuesto. $\mathrm{Su}$ retórica es, por excelencia, el arte del discurso en el que expone la importancia de utilizar la elocuencia para persuadir (Aristóteles, 1999).

Aparentemente, esto está lejos del discurso ficcional, pero si tomamos los principios de lo verosímil veremos que hay un sustento suficiente como para vincular mundos aparentemente tan distantes. Aristóteles distingue la retórica de la poética. La poética es mímesis, es representación de acciones humanas, no busca persuadir, pero sí mostrar aquello que es posible:

Es evidente, a partir de lo que se ha dicho, que relatar lo que ha sucedido no es el trabajo del poeta, sino contar lo que podría haber sucedido, lo posible según la verosimilitud o lo necesario. Pues el historiador y el poeta no se diferencian por expresarse en prosa o en verso [... sino $]$ en decir uno lo que ha sucedido, y el otro lo que podría suceder. (Aristóteles, 1974:157)

Lo que podría suceder es entonces lo verosímil, lo que el otro acepta como probable, no lo verdadero. El punto de encuentro entre retórica y poética es este. La verosimilitud se sostiene, entonces, como lo que encaja en la lógica del otro para ser aceptado como posible: "Es preferible lo imposible verosímil que lo posible verosímil” (Aristóteles, 1974: 223).

Lo creíble para el otro no es un hecho individual, sino que se comparte en una opinión común. La dimensión social de la verosimilitud se explica a partir de que para que una obra tenga credibilidad, ha de compartir la lógica de las interacciones humanas en un contexto definido de modo que lo que resulta verosímil en un entorno determinado puede no resultarlo en otro. Cuando decimos la frase "eso solo pasa en México" estamos aludiendo a esa lógica del contexto que permite la probabilidad de sucesos en un espacio y tiempo definidos.

En 1739, aparece la Poética de Luzan, una obra que desde la teoría literaria nos refuerza estos principios generales sobre la dimensión social de la verosimilitud que es la que corresponde a la retórica y la poética: “(... ) todo lo que es conforme a nuestras opiniones, sean estas erradas o verdaderas, es para nosotros verosímil, y todo lo que repugna a las opiniones que de las cosas hemos concebido" (citado por Matamoro, 2009).

La perspectiva contemporánea de la verosimilitud encuentra vertientes muy valiosas en autores como Genette (1979), Metz (1964) y Todorov (1972), cuyos postulados constituyen el marco de este trabajo para establecer las categorías de análisis utilizadas para abordar la verosimilitud en Game of Thrones.

Para Genette (1979), lo verosímil en un relato depende del grado en que las acciones respondan a un conjunto de principios implícitos compartidos por el público. En Figuras 
III asevera que la verosimilitud se relaciona directamente con la dimensión de los personajes: lo adecuado o conveniente se define en el ámbito de lo humano en un contexto cultural. Es decir, que las acciones verosímiles se reconocerán como verdaderas en la medida en que se adecuan a un sistema de reglas de interacción, el respecto a la norma socialmente reconocida.

En la misma obra, establece la fórmula función más motivación: el personaje debe tener una razón para realizar sus acciones, el relato no puede ser arbitrario en esto. La motivación es el factor indispensable para que una acción pueda leerse como necesaria: ¿por qué hace eso el personaje? Si el espectador encuentra una respuesta lógica, proveniente del devenir de la historia, entonces resultará convincente (Genette, 1979).

El motor de la acción del personaje está en función del objeto de deseo, de acuerdo al modelo actancial de Greimas (1987) que encuentra como elementos básicos de la narración a los pares de opuestos: sujeto/objeto, ayudante/oponente, destinador/destinatario. La lógica de un personaje se encuentra entonces constreñida en su relación con aquello que busca o desea (el objeto puede ser una persona o una situación más abstracta, como obtener poder o salvar al mundo).

En el esquema actancial de Greimas (1987), el concepto de actante está definido por el rol del personaje. El eje sujeto-objeto traza la trayectoria de la acción: el sujeto en busca del objeto, que estará llena de obstáculos, lo cual da sentido al eje ayudante-opositor.

La colección Comunicaciones, serie de publicaciones dirigidas por Eliseo Verón, dedica un número completo al tema: Lo verosímil (1970). En ese tomo se condensan los principios de la verosimilitud en la teoría y su deslizamiento hacia otros textos como el audiovisual.

Iniciemos por la exposición de Todorov en la introducción al tomo: “(...) la finalidad del presente volumen de Communications/Comunicaciones está determinada por esta situación. Nos proponemos aquí mostrar que los discursos no están regidos por una correspondencia con su referente, sino por sus propias leyes..." (Todorov, 1970: 12).

El planteamiento de la verosimilitud en este nuevo contexto de la semiótica trasciende la relación texto-opinión pública de las visiones más antiguas para buscar en los mecanismos internos de las narraciones aquellos elementos que constituyen sus propias leyes para sostener, en ese espacio diegético, lo que es probable y por tanto creíble.

Siguiendo la introducción de Todorov (1970), encontramos el estudio de lo verosímil como la intención de:

(...) sacar al lenguaje de su transparencia ilusoria, de aprender a percibirlo y de estudiar al mismo tiempo las técnicas de que sirve, como el hombre invisible de Wells al beber su poción química, para no existir más a nuestros ojos. (Todorov, 1970: 12)

Kristeva (citada por Vargas, 1993) afirma que lo verosímil está vinculado al sentido que los receptores a través de la semántica y la sintáctica del texto. Así, la verosimilitud semántica quedará definida por la semejanza con un referente, por su identificación o su reflejo, la verosimilitud del contenido. La sintáctica se podría considerar la verosimilitud de la forma. La primera se puede expresar como "esto sí puede pasar en ese contexto", la segunda: "es lógico que pase esto", por la sucesión de acciones previas que lo determinan.

El aspecto sintáctico, estudiado en el análisis de los textos, se compone de elementos como el orden lógico que "reúne todas las relaciones lógicas entre proposiciones" (Ducrot y Todorov, 2011, p. 339), entre ellas la causalidad que integra motivaciones y consecuencias.

Otro elemento es el orden temporal que orienta la sucesión de hechos, así como el orden espacial, que se refiere al espacio creado con mayor o menor semejanza con el referente. En un relato la temporalidad se representa, es decir, la secuencia de hechos en un orden que puede ser lineal o no, desde el punto de vista cronológico, permite al espectador o lector realizar el armado de la temporalidad de toda la historia (Gaudreault y Jost, 1995).

Todorov (2006) afirma que existen tantas formas de verosimilitud como géneros, lo cual deriva en lo que llamaremos verosimilitud genérica. Como indicamos previamente, el género incide en la expectativa del espectador de modo que, a partir del conocimiento previo de cierto tipo de obras, podrá o no hacer concesiones a la verosimilitud. Por ejemplo, el drama realista, ubicado en un espacio y tiempo actuales, obligará al narrador a un alto grado de verosimilitud; en cambio, la comedia romántica, el género fantástico o 
las historias de aventuras permiten muchas concesiones, como las eternas persecuciones de autos en las carreteras norteamericanas, los encuentros fortuitos de una pareja de enamorados o los personajes alegóricos como un perro gigante que vuela. Estas concesiones son aceptadas por el público que da validez a la historia porque la ha ubicado en un género cuyos mecanismos reconoce.

Otro tipo de verosimilitud es la pragmática, definida por Cavillac (citado por Tapia, 2016) como el resultado de los recursos enunciativos que utiliza el narrador en determinadas circunstancias. Está directamente relacionada con la credibilidad del propio narrador y el reconocimiento de sus facultades para narrar una historia. La verosimilitud pragmática se sustenta en la combinación y jerarquización de acciones que dan lógica al relato, y que cuadran en lo que el espectador considera como una experiencia posible.

Un último tipo de verosimilitud que nos interesa para los fines de este trabajo es la diegética, que tiene que ver con la lógica interna de un universo creado. No tanto por sus referentes con las experiencias posibles o con la expectativa del lector, sino por los principios de causalidad y de motivación que sean logrado construir al interior del relato.

Este principio nos permite hablar de verosimilitud en universos diegéticos sumamente alejados de la realidad que vivimos, como los fantásticos, el mundo de los animales, de la magia o de los superhéroes. Podría considerarse que un hecho fantástico no tendría por qué tener verosimilitud, pero sí una historia fantástica concretada en un relato cuyos principios de construcción tienen que atender a la de cualquier narrativa ficcional en términos de estructura dramática, construcción de personajes, líneas argumentales, etc.

\section{La verosimilitud de GOT}

Los episodios de GOT no son auto-conclusivos sino que responden a una estructura argumental sucesiva en la que se presenta la progresión de la trama y en la que los personajes trazan una trayectoria compleja: tienen memoria, aprenden de sus errores, modifican sus objetos de deseo y se interrelacionan de diversas maneras.

La complejidad de la historia no permite identificar un solo protagonista, un héroe, pues uno de los primeros postulados de la serie que al público le quedaron claros es que los héroes pueden morir en cualquier momento, sin haber concluido su misión.

La serie consta de ocho temporadas. Las seis primeras de diez capítulos cada una, la séptima de siete capítulos y la octava de seis, con una duración de 57 minutos, con excepción de los últimos, cuya duración excede de una hora. Dada la imposibilidad de hacer una sinopsis de toda la historia, indicaremos solamente que se trata de un mundo irreal, de tipo medieval (desarrollaré este punto en breve), en el que varias familias de diferentes linajes pelean por el trono de hierro, que representa la obtención del poder total en una geografía imaginaria conocida como los Siete Reinos.

\section{Verosimilitud semántica}

Entendida esta como la semejanza con un referente, empezaré por uno de los aspectos que abonan a la credibilidad de la historia: el contexto medieval.

Si bien la historia transcurre en un lugar inexistente, todos los indicios apuntan a la época medieval: los lugares, las construcciones, la vestimenta, los carruajes, los paisajes, etc. Para comprender la importancia que el reconocimiento del contexto tiene para que el espectador asuma la historia como verosímil, revisemos algunos factores de la construcción del imaginario que el público medio tiene de la Edad Media.

La Edad Media como etapa histórica duró del siglo V al XV d.C. lo que supone un lapso de tiempo demasiado largo como para suponer que fue un período estable y unificado. La mayor parte de los documentos históricos y referencias medievales se encuentran en la iconografía y literatura cristianas, pues la Iglesia fue la institución que logró la unificación en un contexto de dispersión de los poblados, en los que la vida transcurría entre saqueos e invasiones (Gombrich, 1995).

Recupero a continuación una serie de descripciones de la vida medieval, documentadas en las pocas fuentes que dan cuenta de la vida cotidiana de la época:

(...) los historiadores del Bajo Medievo han estudiado lo cotidiano a partir de lo repetitivo, todo aquello que tiene que ver con el ciclo de la propia vida, lo contrario a lo diferente, a lo maravilloso y a lo extraordinario, pero también 
a lo no previsto, como las revueltas sociales, los actos de brujería, las herejías, las guerras, las pestes, los milagros o las catástrofes. (Corral, 2008, p. 12)

La relación del hombre con la naturaleza era estrecha: la concepción del tiempo en función de la hora del amanecer hasta la puesta de sol como definitorios de las jornadas laborales y de la realización de actividades al aire libre. En la oscuridad de la noche ocurrían asesinatos, robos o acciones que no se consideraban propias.

En la cotidianeidad del hombre medieval se encontraban también las inclemencias del tiempo: "El ciclo infernal, característico de sociedades agrarias de débil desarrollo, como sin duda era el caso de la Europa medieval, es bien conocido: naturaleza enfurecida-malas cosechas-hambre-mortandad" (Corral, 2008, p. 20).

El frío invernal, topos central en GOT, era una de las principales amenazas de la naturaleza, que obligó a los hombres a utilizar de manera cotidiana combustibles como la madera y el carbón vegetal, convirtiendo al fuego en el mayor enemigo del frío, y a vestirse con ropajes gruesos y cargados de pieles de animales.

Un mundo rural analfabeta, supersticioso y rústico. Las casas se construían con los materiales a la mano y servían además como graneros y granjas o de talleres en el caso de los artesanos. El mobiliario básico eran las mesas, las camas y las arcas. La vestimenta de los campesinos y los artesanos era burda, sencilla, acromática. Todo esto en contraposición al lujo de las clases acomodadas y el clero en donde encontramos aquellos objetos que prevalecen hasta nuestros días: vajillas, copas, candiles, candelabros, espejos, alfombras, telas suntuosas adornadas con bordados, y objetos conocidos a través de las pinturas de la época (Valdeon, 2004).

La alimentación campesina dependía del cultivo local, de ahí que el pan y el vino hayan constituido la base alimenticia, mientras que los más pudientes tenían acceso a carnes, vegetales y condimentos. También había estas variedades en las ciudades, en las que se empezaron a desarrollar los mercados. La falta de higiene en las ciudades llenas de inmundicia son imágenes frecuentes en el mundo medieval.

La movilidad era común en el medioevo: grandes cantidades de personas peregrinaban por los caminos, huyendo de enfermedades, invasiones o inclemencias de la naturaleza, en carruajes simples jalados por ellos mismos o, los más privilegiados, en caballo. Los caminos solían ser lugares poco seguros por la continua presencia de ladrones:

Con posterioridad al año 1000 la mayor seguridad de las rutas y el incremento de los intercambios, tanto económicos como culturales, propiciaron un espectacular aumento de los desplazamientos. Mercaderes, clérigos, peregrinos, juglares o vagabundos animaron los caminos de la Europa bajomedieval. (Valdeon, 2004, p. 60)

Las relaciones humanas también han sido representadas, aunque no de manera tan descriptiva como los objetos:

La infancia suele ser la gran ausente, y cuando aparece solo lo hace de manera anecdótica y casi siempre personificada en Jesucristo niño, un ser extraordinario cuya vida fue todo lo contrario de una vida «cotidiana». Porque la infancia es un estado en el que los seres humanos casi no lo son, todavía; así lo escribía a comienzos del siglo XIV una mujer de mente tan abierta como la beguina Margarita Porete (...) El amor era algo extraordinario. En una sociedad en la que el matrimonio estaba condicionado por una decisión paterna, el amor no tiene cabida en lo cotidiano, por el contrario, el sexo sí era algo cotidiano. No parece que fuera un tema tabú, como lo será a partir de principios del siglo XVI y hasta bien cumplido el siglo XX. (Corral, 2008, p.12-13)

Por otro lado, las construcciones feudales, pesadas e impenetrables. Las murallas como medida de protección; los valores y objetos derivados de las guerras: armaduras, lanzas, vestimenta militar, la gallardía, el honor, la valentía; la lucha cuerpo a cuerpo y la falta de un orden social que propiciaba la venganza por propia mano.

Todo esto constituye la materia prima del imaginario que el cine y la televisión han construido como "lo medieval". Si bien está consignado en documentos históricos, lo cierto es que la mezcla de estilos y épocas ha generado una imagen estereotipada de la Edad Media, con ambientes 
perfectamente reconocibles por cualquier espectador que resultan verosímiles aun cuando la época exacta resulte equívoca. Basta ver la cantidad de historias sobre las cruzadas, Robin Hood (Scott, 2010) el Rey Arturo (Ritchie, 2017), Juana de Arco (Besson, 1999) o las actuales series de televisión Los Tudor (BBC, Showtime, 2007), lsabel (Diagonal TV, Televisión española, 2012) o Marco Polo (The Weinstein Company/Netflix, 2014).

En todas ellas aparece la misma "estética medieval", que nos familiariza no solo con el entorno sino también con las acciones que son posibles en él. La verosimilitud semántica de Game of Thrones se sostiene en buena medida en la concordancia de la imagen que el público tiene de la época medieval con lo que sucede en la serie. Doy algunos ejemplos:

- Los objetos y escenarios de Winterfell son austeros, dan la impresión de dureza, durabilidad y poco refinamiento. El entorno obliga a sobrevivir en contraposición a la amabilidad climática de Kings Landing, absolutamente mediterránea, en la que florece el color, el lujo y la voluptuosidad. En ambos entornos, sin embargo, reconocemos los guiños de la estética medieval.

- El camino recorrido por Arya Stark la lleva a enfrentar un mundo de ladrones y amenazas que la obligan a desarrollar sus dotes guerreros convirtiéndola en una experta en el uso de armas. Arya, vestida de niño, es capaz de degollar o de atravesar con una espada a prácticamente cualquier adversario. En otro contexto, sería un personaje extremadamente violento; en este es una heroína sobreviviendo a su propio destino.

- Arya se mueve entre el campo salvaje y rústico y las ciudades de calles estrechas y laberínticas, llenas de pordioseros y mercaderes. Presencia la sátira de la muerte de su propio padre en un teatro trashumante; visita templos milenarios y se topa con personajes místicos que encajan muy bien en la época.

- En los matrimonios arreglados de Sansa Stark primero con Joffrey Baratheon, con Tyrion Lannister, y con Ramsay Bolton, no hay romance en ningún caso; hay arreglos familiares o comerciales. Tal es el caso de Margaery Tyrell con ambos príncipes Lannister y de la propia Cersei con Robert Baratheon. El sangriento pasaje de la Boda Roja tiene su origen en la falta de cumplimiento de la palabra de Robb Stark de casarse con la hija de Lord Walder Frey: en ese mundo, no hay amor que justifique la traición.

- El amor se expresa mejor con el cabezazo de Yara a su hermano Theon al ser liberada, que con la escena de Jon y Daenerys en la nieve después de un romántico vuelo en dragón. Esa escena sale del contexto y del tono de la serie. La considero una enorme concesión al público que quiere ver la parte melodramática de GOT, que por cierto, es la más débil.

- La presencia de dragones y brujas es posible en ese mundo. Si bien sabemos que nunca han existido, para la gente medieval constituían parte de su cosmogonía. El dragón es un animal mitológico que aparece en múltiples leyendas (Tolkien, J.R.R.,1982) (Ende, 1983) como símbolo de fuerza invencible, que puede representar al mal, aunque no en todos los casos. La aparición de los dragones en la serie pudo haber ahuyentado al espectador que veía en ella un drama político, una historia de honor y lucha por el poder. Pero fueron siendo insertados de manera sutil y justificada. Volveremos al tema de los dragones al analizar la verosimilitud diegética.

- La brujería era una actividad en la que confluyen saberes y poderes sobrenaturales. Una bruja podía hechizar personas, pero también curar enfermedades. La resurrección de Jon Snow a manos de la bruja fue un hecho que pudo haberse leído como una trampa de los guionistas, recordemos el efecto Reichenbach, que obligó a Sir Conan Doyle a revivir a Sherlock Holmes ante el enojo de los lectores (García, 2012). Sin embargo, lejos de considerarlo una inconsistencia, fue asimilada como una posibilidad real que marcaba al personaje con un nuevo sino: el de la salvación de su pueblo. No se puede resucitar para volver a morir sin haber cumplido su misión.

\section{La verosimilitud sintáctica}

Los créditos iniciales muestran un mapa que, además del goce estético que genera su diseño, dan las claves para 
comprender uno de los puntos nodales de la historia: la lucha por o la defensa del territorio. La noción de territorio encuentra sus bases primero en una localización geográfica que determina las posibilidades de supervivencia y progreso, como la cercanía con el mar, el clima o la fecundidad de la tierra. También marca los límites del ejercicio del poder: las casas Stark, Lannister, Targaryen, Arryn, y demás, son dueñas y señoras de su territorio.

El mapa permite suponer las largas travesías que hay que hacer para ir hacia Winterfell o hacia el Muro. En este sentido, la lejanía entre una escena y otra permite diluir ciertas faltas a la verosimilitud, como la velocidad a la que volaron los cuervos para dar aviso a Daenerys del peligro que corrían Jon y sus acompañantes al ser rodeados por los Caminantes blancos, o el tiempo que pasó para que Jamie Lannister dejara a Cersei para llegar como andante solitario en su caballo a ponerse a las órdenes de los Stark.

Aun así, la lógica espacial de la serie, uno de los factores de la verosimilitud sintáctica, resulta convincente tanto para el espectador que se da a la tarea de estudiar la geografía de Westeros y profundizar en los pormenores de la historia.

En cuanto a la lógica temporal, pensemos que trazar el arco dramático de los personajes de la serie implica un tiro largo, cuya temporalidad es de unos 10 años, de acuerdo a la progresión de la historia y a los indicios que los propios personajes van dando al espectador.

El entramado de historias es quizás uno de los más grandes aciertos de la serie. La sucesión de acontecimientos de un episodio a otro, de una temporada a otra, va siendo causal: no hay acciones que se puedan considerar gratuitas o que queden como hilos sueltos, al menos en un primer visionado de la serie. Esta articulación en el tiempo da credibilidad a la progresión de los personajes y su evolución.

La trayectoria de un personaje debe estar acorde al principio de verosimilitud que impera en la historia. En este caso, al tratarse de un "multirelato" o de un relato polifónico, tenemos múltiples personajes de los cuales la mayoría sufren cambios graduales, a veces de un extremo a otro. Esta es una cualidad del relato serial: permite el desarrollo de personajes en lapsos de tiempo expandidos y en múltiples acciones.

Veamos algunos ejemplos de trayectorias:
- Personajes cambiantes, tipificados como "redondos" por Vanoye (1996), o “densos” (Ducrot y Todorov, 2005): Sansa Stark, Jaime Lannister, Daenerys Targaryen, Theon Greyjoy, Tyrion Lannister, Arya Stark, Bran Stark, Samwell Tarly. Todos ellos han ido modificando sus motivaciones, sus posiciones éticas, sus puntos de vista e incluso sus roles. Si aplicamos en ellos el esquema actancial veremos el mapa de interrelaciones en los que pasan de ayudantes a oponentes del mismo sujeto o del cambio en el objeto que persiguen. Pero los cambios han sido paulatinos y han tenido una causa visible, lo que les da credibilidad. "Los personajes densos deberían definirse por la coexistencia de atributos contradictorios..." (Froster, citado por Todorov, 2006: 262).

- Personajes "chatos" (Ducrot y Todorov, 2006) o planos (Vanoye, 1996): Jon Snow, Cersei Lannister, Jorah Mormont, Little Finger, Sir Davos, Olena Tyrrel, Brienne de Tarth. Estos personajes son consistentes con su propios valores y motivaciones desde el inicio de la serie. La cualidad de chatos o planos no desmerece su construcción ni su trayectoria. Si bien pueden parecer términos peyorativos, en realidad no califican al personaje, sino que indican una consistencia en el motor de sus acciones y las distinciones que tienen como rol.

En ambos casos, personajes chatos o densos, se cumple la premisa de la función-motivación explicada por Genette (1995).

\section{Verosimilitud genérica}

Es difícil ubicar a la serie en los límites de un solo género. En algún sentido, es una historia épica que cuenta historias de héroes legendarios, de grandes hazañas, pero es imposible que todas las fórmulas narrativas y los hechos narrados concuerden solo con la épica.

También es una historia con tintes fantásticos, aunque no es una historia fantástica. En este sentido, utiliza recursos del género al estar ubicada en un mundo imaginario que, siguiendo a Todorov (1970), no cumple las leyes de la naturaleza, de ahí la presencia de los niños del bosque, los dragones y las brujas o la caracterización de Brandon como el 
"cuervo de tres ojos", una suerte de vidente capaz de intervenir en las acciones de otros tiempos.

Pero hay hilos conductores de la serie que apuntan al género dramático-político. El topos más importante de la serie y que constituye la motivación de las acciones más significativas es la lucha por el poder. En ella, están imbricados los principios de la lealtad, el honor, la fuerza, la estrategia, la herencia y los derechos a ocupar un lugar de privilegio, como el trono de hierro. El simbolismo del trono de hierro como poder absoluto, pero legitimado por el linaje en la lógica monacal es importante para justificar las formas utilizadas para recuperarlo; lejos estamos de principios democráticos.

Por último, retomo la aportación de Carrión (2017) al respecto de los géneros de GOT: ha incorporado el del psicópata a un entramado de por sí complejo. Personajes como Joffrey Baratheon y Ramsay Bolton resultan tan consistentes como Dexter (Showtime, 2006) o Hannibal (NBC,2013). También el género de zombies, altamente valorado por el público actual, que hace convivir a los muertos vivientes comandados por el Rey de la Noche con los de The Walking Dead (AMC, 2010), cuya presencia en las pantallas es contemporánea.

El espectador puede ubicar la historia en cualquiera de estos géneros y saber qué esperar del desarrollo de la trama, pues la identificación de las fórmulas y sobre todo de otros discursos parecidos le permite reconocer el mundo posible en el que van a suceder los hechos.

\section{Verosimilitud diegética}

El universo creado por los narradores, utilizando todos los recursos de producción, de lenguaje audiovisual, de desarrollo de personajes, de ambientaciones y sobre todo de sucesión de acciones, dan lugar a una diégesis en la que confluyen los intereses por el poder (no necesariamente por la riqueza, lo cual es interesante), con una serie de elementos sobrenaturales que si bien interfieren en las acciones no son el asunto principal.

Me parece que eso explica el tamaño descomunal de la audiencia de la serie. Veamos el caso de los dragones. Un dragón es un ser creado desde las más antiguas narraciones, como Perseo, Hércules, San Jorge, en muchas culturas occidentales. Sería un recurso bastante gratuito utilizarlo para ganar batallas. Pero su génesis está bien contada, desde el cuidado que Daenerys tiene de los huevos de dragón, su esterilidad y su relación con el fuego como aliado gracias a la intervención de una bruja, justifican la presencia de los dragones, especie que se creía desaparecida en el mundo de la serie, pero que había dado a los Targaryen el poder en tiempos remotos.

La muerte de Viserion a manos del Rey de la Noche da a los dragones la vulnerabilidad suficiente como para que entren a la batalla como un arma más, pero no como la definición absoluta de la victoria, lo cual es un factor importante para la expectativa de la audiencia. El dragón que ahora es una suerte de muerto viviente, entra en el juego a luchar contra sus hermanos, así como los Lannister o los Greyjoy. La lucha entonces no es de fuerza contra fuerza, sino una lucha de estrategia y, sobre todo, de principios, es decir, de motivaciones. Luchar contra los de tu propia sangre implica la presencia de un objeto diferente al inicial, que en los Lannister puede ser su propia reivindicación, o en Theon su dignidad. En todo caso, la batalla final, el momento más esperado de la serie, está circunscrita en una diégesis que no concede resquicios de gratuidad.

\section{El final de la serie: la digresión de la verosimilitud}

Lo expuesto hasta aquí tiene como referente los capítulos de las primeras siete temporadas y los primeros capítulos de la octava, es decir, antes del esperado y, para algunos, decepcionante final (Expansión, 2019) (CNN, 2019).

Independientemente de las condiciones de producción de la serie, que sin duda incidieron en el trabajo guionístico, es importante mencionar el rompimiento con la verosimilitud diegética de los dos últimos capítulos.

La serie sostiene, prácticamente hasta el final, los principios que sustentan la verosimilitud genérica y semántica, es decir, no hay transgresiones al contexto en el que se desarrolla la historia ni a las fórmulas de articulación de elementos de los géneros fantástico y de drama político que encuadran la lógica de la serie. En ese sentido, el espectador encuentra los elementos fácilmente reconocibles de estas dos dimensiones de la verosimilitud cuya solvencia le llevaron a esperar el final. Sin embargo, hay indicios claros 
de pérdida de verosimilitud que han causado polémica entre los espectadores.

En el terreno de lo sintáctico, si bien la elipsis es uno de los recursos fundamentales de la narrativa audiovisual, el armado de la temporalidad no resulta claro para el desarrollo de la trama. Pongo el ejemplo del lapso de tiempo entre la destrucción del trono de hierro por Drogon y el cónclave de notables que, de una escena a otra y mediando solo un corte directo, decidirán todo aquello que justificó los 72 episodios previos: quién gobernará Westeros.

La construcción temporal, base del montaje del discurso audiovisual y por tanto de la lógica narrativa, resulta equívoca en esta escena que, por cierto, es la fundamental para cerrar la historia. ¿Qué pasó en ese lapso? ¿Cómo llegaron hasta ahí los presentes? ¿Quién, en medio de la destrucción, el odio y la incertidumbre, fue capaz de convocarlos y reunirlos en un ambiente en el que, casi rayando en el absurdo, parecen todos dispuestos a conceder?

El flashforward resulta tan largo que no otorga al espectador la información suficiente para comprender la escena siguiente ni para sostener la acción. Por otro lado, en el ámbito de la verosimilitud diegética, quizás el mayor riesgo que corre el último episodio es faltar a los principios que durante la serie fueron los regidores de la interacción de los personajes: la encarnada lucha por del poder, el honor del nombre, la violencia como forma legítima en las relaciones antagónicas o la falta de concesiones al adversario, se ven diluidas en una escena en la que, sin mediar ningún recurso previo, florece lo que podría dar paso en el futuro a un mundo democrático: el acuerdo. Un acuerdo tibio y sin argumentos, sin demasiados sobresaltos, que deja en el trono a un personaje que, durante su arco dramático, había dejado de ser humano, había dejado de ser Brandon Stark para convertirse en el Cuervo de tres Ojos y que de manera aparentemente gratuita recupera su condición primera para hacerse cargo de aquello que desdeñó durante el desarrollo de la trama.

Dejo aquí estos ejemplos pues no es la intención de este trabajo realizar una valoración de la serie en términos de su popularidad, sino atender a los principios que la hacen verosímil a la luz de los postulados revisados en la primera parte.

\section{Conclusiones}

El avance de una serie de estas características, ha generado una expectativa en las audiencias que deja en claro que el final no está resultando predecible. Como en la mayoría de las historias épicas, en las que el bien siempre triunfa sobre el mal, este no es un final "epifánico", en términos de Zavala (2005), pero tampoco se espera un final abierto o ambiguo. Los más de 38 millones de espectadores seguramente serán sorprendidos por una serie fantástica que ha resultado de un realismo contundente.

Pero en términos del análisis de la serie, la identificación de los elementos que logran la conformación de una diégesis convincente, que invita al espectador a realizar lo que en el teatro se conoce como la "suspensión voluntaria de la incredulidad" (Carreter, 2019), requiere necesariamente de la disección de sus partes. Realizar esta tarea desde las categorías emanadas de los distintos tipos de verosimilitud resulta un ejercicio sencillo como una primera aproximación a la serie, entendida desde sus múltiples aristas.

Este trabajo es, por tanto, el inicio de un análisis profundo de los elementos narrativos y formales de Game of Thrones, que brindan una panorámica general desde la cual se puede explicar el pacto de lectura logrado con la audiencia, por un lado, pero por otro, constituye un punto de partida para considerar lo que es un relato de calidad y entrar a estudiar sus mecanismos internos con miras a la comprensión de uno de los fenómenos mediáticos más llamativos de la actualidad. Un análisis de esta naturaleza trasciende el plano de la opinión, del gusto popular o de la crítica de series orientadas a atraer tráfico hacia las plataformas en las que hay noticias o presencia de la serie. El objetivo, desde las ciencias sociales, está planteado en función de la comprensión de un hecho que no es menor: el espectador en la actualidad se expone a cientos de horas de ficción, a relatos que al ser verosímiles adquieren el status de verdadero, y entonces constituyen un marco referencial para el comportamiento humano, legitiman formas de pensar, normalizan situaciones sociales, logran empatía con personajes que enfrentan dilemas morales al tomar decisiones en su actuar. Las series en la actualidad constituyen el gran paradigma de la ficción cuya gramática está desarrollada a tal grado que resultan más realistas que los géneros informativos o documentales. 


\section{Referencias}

AP (15 de abril, 2019). Game of Thrones anota récord de audiencia con 17.4 millones de espectadores en arranque de temporada. El Economista. Recuperado de: https: //bit.ly/2nGCQVr

Aristóteles (1974). El arte poética. Madrid, Gredos, 1448, 20. Aristóteles (1999) Retórica. Madrid: Editorial Gredos.

Barthes, R.; Boons, M.; Burgelin, O.; Genette, G.; Gritti, J.; Kristeva, J.; Metz, C.; Morin, V.; Todorov, T. (1970) Lo verosímil. Buenos Aires: Editorial Tiempo Contemporáneo.

Carrión, J. (2017). Teleshakespeare. Barcelona: Ed. Errata Naturae.

Cascajosa, C. (2009). La nueva edad de oro de la televisión norteamericana. Secuencias, revista de Historia del Cine. 29. Recuperado del Repositorio UAM: https://bit.ly/2 KH9Dkc

Cascajosa, C. (2016). La cultura de las series. Barcelona: Ed. Laertes/Kaplan

Carreter, C. (30 de agosto, 2017) Verdad, verosimilitud, incredulidad, a propósito de Game of Thrones. [Blog] Cuaderno de Ruta 3.0 Diario no diario de Carlos Carreter. Recuperado de: https://bit.ly/2pqYvBt

Corral Lafuente, José Luis. (2008) La idea de lo cotidiano en la pintura de la Baja Edad Media, en Lacarra, Ducay, Ma. del Carmen. Arte y vida cotidiana en la época medieval. Zaragoza, España: Institución Fernando el Católico.

Ducrot, O. y Todorov, T. (2011). Diccionario enciclopédico de las Ciencias del lenguaje. México: Siglo XXI editores.

Ende, Michael. (1983). La historia interminable. Madrid: Alfaguara

García, A. (2012). Una máquina de contar historias. Complejidad y revolución del relato televisivo. Barcelona: UTECA.

García, S. (2018). Poética de Aristóteles. España: Editorial Gredos.

Gaudreault F. y Jost (1995). El relato cinematográfico. Barcelona: Paidós.

Genette, G. (1979). Figuras III. Buenos Aires: Editorial Lumen.

Greimas, A. (1987). Semántica estructural. Barcelona: Editorial Gredos.

Gombrich, E. (1995). Historia del arte. México: Editorial Diana.

Hernández, J. y García, M. (1994). Historia breve de la Retórica, Madrid: Síntesis.

Hernández Guerrero, José Antonio y María del Carmen García Tejera. (1994). Historia breve de la Retórica. Madrid: Síntesis, 1994.
Lacarra, M. (2008). Arte y vida cotidiana en la época medieval. Zaragoza, España: Institución Fernando El Católico.

Matamoro, B. (2009). La verosimilitud: historia de un pacto. Alicante: Biblioteca Virtual Miguel de Cervantes.

Metz, Christian (1964-1968). Ensayos sobre la significación del cine. Barcelona: Paidós

Mittel, J. (2015). Complex TV. The Poetics of Contemporary Television Storytelling. Nueva York y Londres: New York University Press.

Platón (trans. 1871). Gorgias en Platón, Obras completas. Madrid: Edición de Patricio de Azcárate.

Tapia, Miguel (2016). La construcción de la verosimilitud en la crónica contemporánea en America. Cahiers du Criccal. No. 49. Recuperado en línea el 240419. https: //journals.openedition.org/america/1768?lang=en

Thompson, R. (1997). Television's Second Golden Age. Nueva York: Syracuse University Press.

Todorov, T. (2006). Introducción a la literatura fantástica. Barcelona: Paidós.

Todorov, Tzvetan et al. (1970). Lo verosímil. Colección Comunicaciones. Buenos Aires: Ed. Nueva Imagen.

Tubau, D. (2014). El guion del siglo XXI. Barcelona: Alba Editorial.

Tolkien, J.R.R. (1982). El Hobbit. Barcelona: Ed. Minotauro

Valdeón, J. (2004). Vida cotidiana en la Edad Media. Madrid: Editorial Dastin

Vanoye, Francis (1996). Guiones modelo y modelos de guion. Barcelona: Paidós.

Vargas, J. (1993) La verosimilitud. Revista de Filología y Lingüística. XIX (1) Pag. 7-16.

Zavala, L. (2005). Manual de análisis narrativo. México: Editorial Trillas.

\section{Sitios web}

Carrión, Jorge. Game of Thrones: la serie rabiosamente contemporánea. 17 de agosto, 2017. https://www.el tiempo.com/lecturas-dominicales/game-of-thrones-es -analizada-por-jorge-carrion- 119760

CNN. ¿Por qué los fanáticos de Game of thrones están tan molestos con la última temporada? https://cnnespanol.c nn.com/2019/05/18/por-que-los-fanaticos-de-game-of -thrones-estan-tan-molestos-con-la-ultima-temporada/

Entrepeneur. \#GOT se queda con el trono de hierro en las Redes Sociales. Artículo del staff del portal. https://www. entrepreneur.com/article/334024 Recuperado el 120519

Excelsior. Game of thrones batió su propio record de audiencia. https://www.excelsior.com.mx/funcion/game-thrones-batio-su-propio-r

Expansión. Los fans de 'Game of Thrones' firman para que HBO rehaga la última temporada. Recuperada el 160519 https:/expansion.mx/tendencias/2019/05/16/los-fans- 
de-game-of-thrones-firman-para-que-hbo-rehaga-la-u lima-temporada

López, Maximiliano (2012). La irrupción del realismo en el género fantástico https://elgranotro.com/game-of-thron es-la-irrupcion-del-realismo-en-el-genero-fantastico/

\section{Películas}

Besson, Luc. (Director), Ledoux, Patrice (Productora). (1999). Juana de Arco. EUA: Gaumont Film Company, Columbia Pictures.

Ridley, Scott (director), Brian, Razel y Rusell Crow (productores). (2010). Robin Hood. Estados Unidos: Universal Pictures.

Ritchie, Guy (Director), Goldsman, Akiva (productor). (2017). El Rey Arturo. UK, EUA: Warner Bros.

\section{Series}

Benioff, David y D.B Weiss. (2011) Game of Thrones. Estados Unidos: HBO

Hirst, Michael. (2007) Los Tudor. Estados Unidos: Showtime, Working Title Films.

Olivares, Javier. (2012). Isabel. España: Diagonal TV, Televisión española.

Fusco, John. (2014) Marco Polo. EUA: The Weinstein Company.

Manos Jr. James. (2006). Dexter. EUA. Showtime networks. Fuller, Bryan. (2013). Hannibal. EUA: NBC 